\title{
Differential expression of prostaglandin $F$ receptor in goat endometrium during estrous cycle and early pregnancy
}

\author{
Rohit Kumar ${ }^{1}$, P.W. Ramteke ${ }^{1}$, Amarnath ${ }^{2}$ and Sanjeev Kumar Sharma ${ }^{3}$
}

1. Jacob School of Biotechnology and Bioengineering, Department of Biological Sciences, Sam Higginbottom Institute of Agriculture, Technology \& Sciences, Allahabad (Uttar Pradesh) 211007, India; 2. Division of Surgery, Indian Veterinary Research Institute, I zatnagar, Bareilly (Uttar Pradesh) 243122, India; 3. Physiology and Reproduction Division, Central Avian Research Institute, Izatnagar, Bareilly (Uttar Pradesh) 243122, India

Corresponding author: Rohit Kumar, Tel No: +91-9450428283, +91-7376411066, email: rohit2005biotec@gmail.com

Received: 06-09-2013, Revised: 28-10-2013, Accepted: 28-10-2013, Published online: 13-12-2013

doi: 10.14202/vetworld.2013.978-981

How to cite this article: Kumar R, Ramteke PW, Amarnath and Sharma SK (2013) Differential expression of prostaglandin F receptor in goat endometrium during estrous cycle and early pregnancy, Veterinary World 6(12): 978-981

\begin{abstract}
Aim: Present study was undertaken to investigate profiling of prostaglandin F receptor (PGFR) mRNA expression during estrous cycle and early pregnancy.

Materials and Methods: Female genitalia of goats $(n=3)$ were collected from a local abattoir. Based on color, vasculature, size, and consistency of corpus luteum (CL), the uteri were classified into three stages of the estrous cycle: stage I: Days 3-5; stage II: Days 6-15, stage III: Days 16-21 and early pregnancy ( $<30 \mathrm{~d}$ foetus). Total RNA was isolated from endometrial scrapings of respective uteri and reverse transcribed followed by DNase treatment. cDNA was used as template to assess gene expression. Expression profiling was performed for PGFR gene using Real Time quantitative PCR (RT-qPCR).
\end{abstract}

Results: At the time of luteolysis the expresion of PGFR was found to be high. However, during pregnancy the expression of PGFR was high as compared to stages of estrous cycle.

Conclusion: Higher expression of PGFR at stage III showed luteolytic signal during estrous cycle. However, peaked expression during pregnancy revealed that the conceptus could be responsible for upregulated expression of PGFR in the endometrium during the implantation period.

Key words: early pregnancy, goat, estrus cycle, prostaglandin F Receptor, prostaglandin F2 $\alpha$

\section{I ntroduction}

Prostaglandins (PGs) act as a most important regulator of female reproductive functions and associated pathologies [1]. Among different classes of PGs, PGF $2 \alpha$ is one of the important prostanoids, produced by bovine and human endometrium [2,3]. It regulates ovarian cycle through initiating the regression (luteolysis) of CL and functions as major luteolytic agent [4,5]. Luteolysis has defined as functional and/or structural regression of CL regressed to permit a new ovarian cycle $[4,5]$. Conversely, the function and integrity of the CL are required to establish and maintain pregnancy. In domestic species, luteolysis must be initiated to permit a new ovarian cycle to begin when conception does not occur. The major route in PGF $2 \alpha$ formation is via reduction of PGH2 by 9, 11-endoperoxidase reductase activity. After biosynthesis, PGF2 $\alpha$ is rapidly transported out of the cell, once released it acts in an autocrine or paracrine manner. Prostaglandins mediate their effects through membrane-bound receptors in the uterus [6]. PGF2 $\alpha$ exert its biological function through interactions with a member of the G-protein coupled receptors (FP prostanoid receptors; PGFR) [7]. Therefore, PGFR is found to be associated for both,

Copyright: The authors. This article is an open access article licensed under the terms of the Creative Commons Attribution License (http://creativecommons.org/licenses/by/2.0) which permits unrestricted use, distribution and reproduction in any medium, provided the work is properly cited. luteolysis [8] and establish/mainatanance of early pregnancy [9].

Expression of PGFR during estrous/mesuration cycle have been reported in human, horse, and cow endometrium $[6,10,11]$. However, during early pregnancy its expression was studied only in rat and pig endometrium $[9,12]$. Although, goat is considered as one of important livestock species with high economic value, the information on expression profiles of PGFR has not been reported yet. Considering the importance of PGFR in regulation of estrous cycle and embryo survivability, the present study is proposed to investigate its expression profile in goat endometrium during estrous cycle and early pregnancy.

\section{Materials and Methods}

Tissue collection: Female goat genitalia $(n=3)$ were collected from a local abattoir and transported immediately to the laboratory on ice. Uteri specimens were washed with sterile phosphate buffer saline. Based on color, vasculature, size and consistency of CL in cow, buffalo, and goat the uteri were classified into three stages of the estrous cycle: stage I: Days 3-5; stage II: Days 6-15 and stage III: Days 16-21 [13-16]. The age of foetus was determined $(<30 \mathrm{~d})$ on the basis of cranial length and weight. Uteri were opened longitudinally followed by scrapping of endometrial tissues from the uterus using RNase free glass slides. While in the gravid uteri, embryo/foetus along with the 
Table-1. Primers used in real time PCR

\begin{tabular}{lllcr}
\hline Sr. No. & Genes & Primer sequences $\left(\mathbf{5}^{\prime} \rightarrow \mathbf{3}^{\prime}\right)$ & Primer Concentration & Amplicon size \\
\hline 1. & GAPDH & F: CTCCTGCACCACCAACTG & $100 \mathrm{nM}$ & $188 \mathrm{bp}$ \\
& & R:CGCCAGTAGAAGCAGGGA & $50 \mathrm{nM}$ & $114 \mathrm{bp}$ \\
2. & PGFR & F: TACTTTTTCTTTCTGGGCTCC & $100 \mathrm{nM}$ & $100 \mathrm{nM}$ \\
\hline
\end{tabular}

foetal membranes was carefully removed and the intercaruncular endometrium tissues were collected. The specimens showing any abnormality or inflammatory conditions were discarded. Tissue samples were collected from middle and cranial part of the ipsilateral and contralateral uterine horns. Tissues were kept in RNA later (Ambion, USA) at $-80^{\circ} \mathrm{C}$ until used.

RNA isolation and CDNA synthesis: Total RNA was isolated using TRI reagent (Sigma, USA) following the manufacturer's instructions. The RNA samples were treated with DNase using DNA-free DNase kit (Ambion, USA). The concentration and purity of RNA was determined spectrophotometrically at $\mathrm{OD}_{260}$ and $\mathrm{OD}_{280}$ and the integrity was examined by electrophoresis. Total RNA was reverse transcribed using Revert Aid cDNA synthesis kit (Fermentas, USA) following manufacturer's instructions. Briefly, the cDNA was synthesized from $1 \mu \mathrm{g}$ total RNA using random hexamer primers in a final volume of $20 \mu \mathrm{l}$. The resultant first strand cDNA was stored at $-80^{\circ} \mathrm{C}$ until further use.

Real time quantitative PCR (RT-qPCR): The mRNA expressions of the target and reference gene was quantified using RT-qPCR. The glyceraldehyde 3phosphate dehydro-genase (GAPDH) was used as an endogenous reference gene. The gene specific primers were designed using Primer3Plus online software tool (http://www.bioinformatics.nl/cgi-bin/primer3plus/ primer3plus.cgi/) (Table-1). The RT-qPCR was carried out using iQ5 real-time PCR system (Bio-Rad, USA). All the PCR reactions were performed in triplicates in a final reaction volume of 20 $\mu$ l containing Maxima SYBR Green qPCR (Fermentas, USA), gene-specific primer (Table-1) and $4.0 \mu 1$ of cDNA (40ng) as template. Universal PCR cycling conditions were set as: initial denaturation at $95^{\circ} \mathrm{C}$ for $10 \mathrm{~min}, 40$ cycles of $95^{\circ} \mathrm{C}$ for $30 \mathrm{sec}, 60^{\circ} \mathrm{C}$ for $20 \mathrm{sec}, 72^{\circ} \mathrm{C}$ for $20 \mathrm{sec}$, followed by a dissociation stage of $95^{\circ} \mathrm{C}$ for $1 \mathrm{~min}$, $60^{\circ} \mathrm{C}$ for $20 \mathrm{sec}$ and $95^{\circ} \mathrm{C}$ for $30 \mathrm{sec}$. In order to rule out the possible DNA contamination for each RNA sample a no-RT control reaction was set up in which reverse transcriptase enzyme was omitted during cDNA synthesis. To determine the specificity of the PCR reaction, a dissociation curve was generated after the completion of amplification.

Statistical analysis: Levels of expression of caprine PGFR mRNA were analyzed using $2^{-\Delta \Delta C T}$ method (Livak and Schmittgen, 2001) and expressed as fold change relative stage III. Subsequently, differences between groups were statistically analyzed by one way
ANOVA. All numerical data were expressed as a mean \pm SEM of 3 biological replicates from each reproductive stages.

\section{Results}

Expression profile of PGFS and PGFR: Relative quantification of PGFR transcripts was determined by Real Time PCR. We observed significantly lower mRNA expression of PGFR at stage I and II, in comparison to stage III $(\mathrm{P}<0.01)$. However, its expression was approximately fifteen fold higher $(\mathrm{P}<0.01)$ in pregnancy than stage III of estrous cycle. Similarly in horse, the expression was found to be increased towards luteal phase, but its expression was constantly low during early pregnancy [6]. In contrast, the PGFR was expressed at low levels and there were no changes in its level during the estrous cycle in bovine endometrium [17].

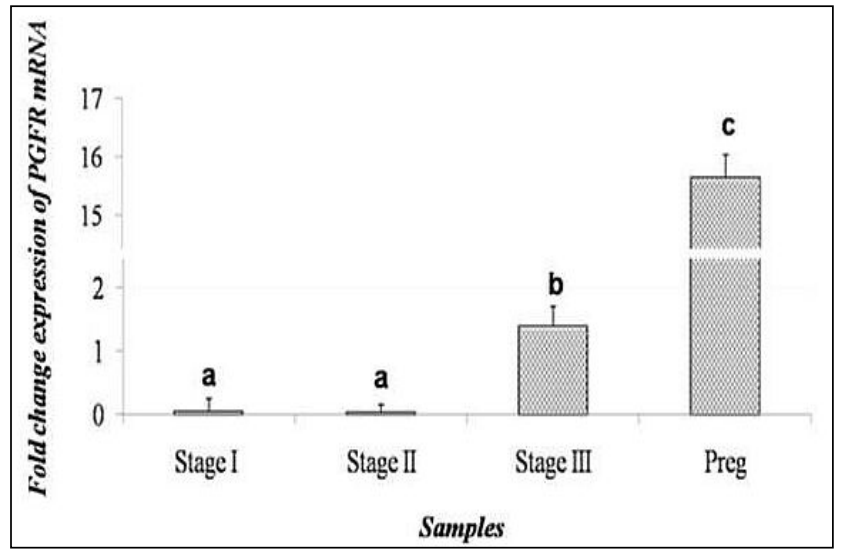

Figure-1. Expression of PGFR mRNA during the estrous cycle and pregnancy of goat. Uncommon superscripts represent a statistical difference $(P<0.05)$ between stages of estrous cycle and gestation.

\section{Discussion}

Both, estrous cycle and pregnancy is regulated by a functional mediator of luteolytic signal PGF2 $\alpha$. Luteolysis is mediated by the release of luteolytic pulses of PGF2 $\alpha$ by the uterus at the end of diestrus, which must be suppressed by the conceptus to permit maternal recognition of pregnancy. Presence of PGFR in the caprine endometrium is in agreement with detection of this receptor in uterus of ovine [18], equine [6], bovine [19], murine [12], and porcine [9]. We observed a high expression of PGFR mRNA in goat at stage III as compared to stage I and II during estrous cycle, which corresponds to elevated level of PGFS reported in several species $[9,12]$. However, its expression was much higher during pregnancy than stages of estrus cycle.

High expression of PGFR in the goat endometrium corresponds to luteolytic signal of PGF $2 \alpha$ as reported 
in porcine endometrium [9]. In order to permit a new ovarian cycle through luteolysis by regression of the CL the expression of PGFS and its receptor PGFR turn out to be more at luteolytic stage/late diestrous (stage III). The upregulated transcripts of PGFR may indicate a coordination of events which result in biosynthesis and action of PGF2 $\alpha$ in the endometrium leading to luteolysis in goats as reported earlier in equine also [6]. Higher expression of PGFR in goat endometrium at early pregnancy amongst cyclic stages was in consistent with porcine [9] and rat [12] endometrium. Here, the elevated expression of PGFR also corresponds with increased concentrations of PGF2 $\alpha$ in pregnant pigs [20]. As reported earlier, a luteotropic signal PGES produced in response to embryo, could be involved for huge amount of PGFR production. The high expression of PGFR in goat endometrium in response to PGES is in consistent with porcine, but the mechanism underline this event is remains to be explored.

Appropriate coordination between PGFS and PGFR biosynthesis and secretion is important either during the luteolysis initiation or during the establishment of pregnancy [6,21]. These results suggest that there is an orchestrated chain of events that regulates prostaglandin biosynthesis and action in favour of regulation of estrous cycle and pregnancy in goat endometrium. We also report that, there is species variation of expression pattern of PGFR gene, even amongst ruminants also. Hence, here we established a basal level of information of temporal expression of mRNA for PGFR gene in goat.

\section{Conclusion}

In this study, for the first time we have determined the relative abundance of PGFR mRNA at different stages of estrous cycle and during early pregnancy. We conclude that PGFR could be associated with both luteolysis and pregnancy. The results have laid down the basic idea about relative expression of PGFR in goat endometrium. Further efforts are needed to investigate the function of peaked expression of PGFR during early pregnancy.

\section{Authors' contributions}

RK and PWR designed the study. RK has performed the experiment. A. and SKS helped RK for draft and revision of manuscript. All authors read and approved the final manuscript.

\section{Acknowledgements}

The authors would like to thank Vice Chancellor, Sam Higginbottom Institute of Agriculture, Technology and Sciences (SHIATS) Allahabad, (UP), India. The work has been carried out during PhD studentship of RK Since this work has been carried out during research work of $\mathrm{RK}$ for $\mathrm{PhD}$. Therefore vice chancellor of SHIATS is the sole source of funding.

\section{References}

1. Lindstrom, T. and Bennett P. (2004) Transcriptional regula- tion of genes for enzymes of the prostaglandin biosynthetic pathway. Prostaglandins, Leu. Ess. Fat. Aci.,70 (2),115-135.

2. Madore E., Harvey N., Parent J., Chapdelaine P., Arosh J. A.

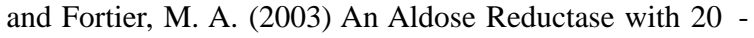
Hydroxysteroid dehydrogenase Activity is Most Likely the enzyme responsible for the production of Prostaglandin F $2 \alpha$ in the Bovine Endometrium, J. Biol. Chem., 278,13-28.

3. Chapdelaine, P., Kang, J., Boucher-Kovalik, S., Caron, N., Tremblay, J. P. and Fortier, M. A. (2006) Decidualization and maintenance of a functional prostaglandin system in human endometrial cell lines following transformation with SV40 large T antigen. Mol. H. Reprod., 12: 309-319.

4. Arosh, J. A., Banu, S. K.,Chapdelaine, P., Madore, E., Sirois, J. and Fortier, M. A. (2004) Prostaglandin biosyntheis, transport and signaling in CL, a basis for autoregulation. Endocrinolgy, 145: 2551-2560.

5. McCracken, J. A., Custer, E. E. and Lamsa, J. C. (1999) Luteolysis: a neuroendocrine-mediated event. Physiol. Rev., 79: 263-323.

6. Atli, M. O., Kurar, E., Kayis, S. A., Aslan, S., Semacan, A., Celik, S. and Guzeloglu, A. (2010) Evaluation of Genes Involved in Prostaglandin Action in Equine Endometrium During Estrous Cycle and Early Pregnancy. Ani. Reprod. Sci., 122:124-32.

7. Kumar, R., Ramteke, P. W., Nath A., Pramod, R.K., Singh, S.P., Sharma, S.K., and Kumar S. (2013) Role of Candidate Genes Regulating Uterine Prostaglandins Biosynthesis for Maternal Recognition of Pregnancy in Domestic Animals, ISRN Phys. http://dx.doi.org/ 10.1155/ 2013/854572.

8. Boonyaprakob U., Gadsby J.E., Hedgpeth V., Routh P.. and Almond G.W. (2003) Cloning of pig prostaglandin F2alphaFP receptor cDNA and expression of its mRNA in the corpora lutea. Reproduction, 125:53-64.

9. Kaczynski, P. and Waclawik A. (2013) Effect of conceptus on expression of prostaglandin F2a receptor in the porcine endometrium, Theriogenology, 79: 784-790.

10. Stuart, A., Milne and H. N. and Jabbour (2003) Prostaglandin (PG) F2 $\alpha$ Receptor 534 Expression and Signaling in Human Endometrium: Role of PGF2 $\alpha$ in Epithelial 535 Cell Proliferation. J. Clin. Endocrinol. Metabol., 88: 1825-1832.

11. Ulbrich, S. E., Schulke, K., Groebner, A. E., Reichenbach, H. D., Angioni, C., Geisslinger, G. and . Meyer H. H. D. (2009) Quantitative characterization of prostaglandins in the uterus of early pregnant cattle. Reproduction, 138: 371-382.

12. Dong Y. L. and Yallampalli C. (2000) Pregnancy and exogenous steroid treatments modulate the expression of relaxant $\mathrm{EP}(2)$ and contractile FP receptors in the rat uterus, Biol. Rep., 62(3):533-9.

13. Arosh, J. A., Parent, J., Chapdelaine, P., Sirois, J. and Fortier, M. A. (2002) Expression of cyclooxygenases 1 and 2 and prostaglandin E synthase in bovine endometrial tissue during the estrous cycle. Biol. Rep., 67: 161-169.

14. Yadav, V. K., Sudhagar, R. R. and Medhamurthy R. (2002) Apoptosis during spontaneous and prostaglandin F(2alpha)induced luteal regression in the buffalo cow (Bubalus bubalis): involvement of mitogenactivated protein kinases. Biol. Rep., 67: 752-759.

15. Verma-Kumar, S., Srinivas, S. V., Muraly, P., Yadav, V. K. and Medhamurthy, R. (2004) Cloning of a buffalo (Bubalus bubalis) prostaglandin F (2alpha) receptor: changes in its expression and concentration in the buffalo cow corpus luteum. Reproduction, 127, 705-715.

16. Tereza, M. M., Moura, M., Fonseca, V. U., Silva, N. B., Freitas, M. L., Almeida, O. B., Rocha, H. A. O., Papa, P. C. and Moura, C. E. B. (2010) Morphological features and vascularization study of caprine cyclic corpus luteum. Pesq. Veterin. Brasil., 30: 351-357.

17. Arosh, J. A., Banu S. K., Kimmins, S.,Chapdelaine, P., Laren, M. L. A. and Fortier, M. A. (2004) Effect of IFN-t on prostaglandin biosynthesis, transport and signaling at the time of maternal recognition of pregnancy in cattle: evidence of polycrine action of prostaglandin E2. Endocrinology, 145: 
5280-5293.

18. Dorniak, P., Bazer, F. W. and Spencer, T. E. (2011) Prostaglandins regulate conceptus elongation and mediate effects of interferon tau on the ovine uterine endometrium. Biol. Repr., 84:1119-27.

19. Fortier, M. A., Arosh, J. A., Banu, S.A. and Chapdelaine, P. (2004) Temporal and tissuespecific expression of prostaglandin receptors EP2, EP3, EP4, FP, and cyclooxygenases 1 and 2 in uterus and fetal membranes during bovine pregnancy. Endocrinology, 145:407-17.
20. Waclawik, A., Blitek, A., Kaczmarek, M. M., Kiewisz, J. and Ziecik A. J. (2009) Antiluteolytic mechanisms and the establishment of pregnancy in the pig. Soci. Reprod. and Fert. Supp., 66: 307-20.

21. Kaczmarek M. M., Blitek A., Kaminska K., Bodek G., Zygmunt M., Schams D. and Ziecik A. J. (2008) Assessment of VEGF-receptor system expression in the porcine endometrial stromal cells in response to insulin-like growth factor-I, relaxin, oxytocin and prostaglandin E2. Mol. Cell. Endo., 291:33-41.

$* * * * * * * *$ 